\title{
Sea buckthorn Hippophae rhamnoides a non-conventional source of edible oil
}

\author{
Sabiha Rashid ${ }^{1}$, Amina Arif ${ }^{*}$, Amna Tabasum², Hina Zain ${ }^{3}$, Shahana \\ Ehsan $^{4}$ and Muhammad Shafeeq Ur Rahman ${ }^{5}$ \\ 1. Faculty of Life Ssciences, University of central Punjab, Lahore-Pakistan \\ 2. Department of Chemistry, University of Education, Lahore-Pakistan \\ 3. Allied Health Sciences, Superior University, Lahore-Pakistan \\ 4. Department of Chemistry, Lahore College for Women University, Lahore \\ 5. Faculty of Pharmacy, University of central Punjab, Lahore-Pakistan \\ *Corresponding author's email: dr.amina@ucp.edu.pk
}

Citation

Sabiha Rashid, Amina Arif, Amna Tabasum, Hina Zain Shahana Ehsan and Muhammad Shafeeq Ur Rahman. Sea buckthorn Hippophae rhamnoides a non-conventional source of edible oil. Pure and Applied Biology. Vol. 9, Issue 1, pp1040-1048. http://dx.doi.org/10.19045/bspab.2020.90109

Received: 12/10/2019 Revised: 01/12/2019 Accepted: 13/01/2020

Online First: 20/01/2020

\section{Abstract}

Obtaining edible oil from animals and plant sources is an ancient practice of the people in the tropical regions of the globe. Industrialization of oil and fats began with the creation of a cotton seed mill, due to higher demand several different plants have been studied to get good and healthy oil and fats. In this research the fixed oil from the berries of Sea Buckthorn was characterized and studied for its fatty acid composition by biochemical tests and Gas Chromatography Mass Spectroscopy (GCMS). The chemical characteristics of oil from seeds showed the saponification value 248.36 , iodine value 80.49 and free fatty acid value $11.28 \%$. While the identified fatty acids were palmitic acid $(\mathrm{C} 16,0) 24.98 \%$, oleic acid $(\mathrm{C} 18,1) 20.97 \%$, linoleic acid $(\mathrm{C} 18: 2) 11.51 \%$, linolenic acid 4.31(C18:3) \%, and stearic acid $(\mathrm{C} 18,0) 0.29 \%$. The fatty acid profile and physico chemical value of the oil showed that oil has health promoting chemistry and good source of energy. These findings provide essential data explaining that the oil obtained from the berries is nothing less than any other good quality of edible oil.

Keywords: Edible oil; Fixed oil; Gas chromatography mass spectroscopy; Sea Buckthorn

\section{Introduction}

Sea Buckthorn is a wild bush of arid soils or sandy wasteland. Sea Buckthorn is spelled sometime together as Seabuckthorn or Sea Buckthorn. The name is related to the fact that it is used to grow on sand dunes along the sea beaches. It is also worth mentioning that Sea Buckthorn has nothing in common with regular Buckthorn. These are two different plants from different families. Sea Buckthorn first added value to human health in $8^{\text {th }}$ century [1].
Sea Buckthorn since 1950's has been studied extensively due to its nutritional and medical importance. Seeds, berries, leaves and bark of Sea Buckthorn having important value [2]. According to Russian and Chinese scientists, Sea Buckthorn contains 190 bioactive components out of which, the oil has been identified as the major functional component in Sea Buckthorn [3] and is the best single source. Oil present in the Sea Buckthorn is not only an essential oil but it is a fixed oil [4]. Fixed oil contains unsaturated fatty acids 
especially acyl glycerol. The free fatty acid contents of a crude fat is usually dependent on the degree to which the fat has been subjected to enzymatic hydrolysis. In fats of good quality, it is not ordinarily greater than $1 \%$ palm oil and greases are characteristically high in free fatty acid $3.30 \%$. Fats contain small amount (1-2\%) of unsaturated and saturated hydrocarbons, which appear with sterols in non-saponifiable matter. Majority of the naturally occurring fats have fatty acids molecules of chain length more than 16 carbon atoms. Fixed oils are generally classified into drying, semi drying and nondrying oils according to the iodine value [5]. Chemical and physical properties of all the fixed oils are dependent on the esterification of fatty acids with glycerol.

Sea Buckthorn berries or seeds pulp contain adequate amount of C16 fatty acids, carotenoids, tocopherols, vitamin $\mathrm{E}$ and $\mathrm{C}$ [6]. More than $90 \%$ of the total fatty acids are unsaturated fatty acids. Sea Buckthorn oil contains Omega-3 (28-30\%) Omega-6 (36$40 \%)$ and Omega-9 (17-20\%) oil containing (n-3) and (n-6) fatty acids and antioxidants [7]. Vitamin E content in Sea Buckthorn oil is two times higher than wheat oil, 9 times higher than corn oil and 35 times higher than soybean oil $[8,9]$. Oil content present in the compounds of Sea Buckthon berries is of highly nutritional and medicinal importance [10]. Sea Buckthorn oil also shows minor proportion of antioxidant activity [11, 12]. Sea buckthorn berries not only contain fixed

Table 1. Chemical contents of oil

\begin{tabular}{|c|c|}
\hline Chemical content & Amount $^{\wedge}$ \\
\hline Free Fatty Acid Value $(\%)$ & $11.28 \pm 0.3$ \\
\hline Acid Value $(\mathrm{mg} \mathrm{NaOH} / \mathrm{g})$ & $22.48 \pm 0.5$ \\
\hline Peroxide Value $(\mathrm{mg} \mathrm{KOH} / \mathrm{g})$ & $70 \pm 0.4$ \\
\hline Iodine Value $(\mathrm{g} \mathrm{I} / 100 \mathrm{~g})$ & $80.49 \pm 0.3$ \\
\hline Saponification Value $(\mathrm{mg} \mathrm{KOH} / \mathrm{g})$ & $248.36 \pm 0.7$ \\
\hline Unsaponifiable Matter $(\%)$ & $3.03 \pm 0.03$ \\
\hline Specific gravity $(\mathrm{g} / \mathrm{mL})$ & $0.922 \pm 0.005$ \\
\hline Refractive Index at $28^{\circ} \mathrm{C}$ & $1.462 \pm 0.004$ \\
\hline Moisture Content $(\%)$ & $0.013 \pm 0.01$ \\
\hline
\end{tabular}

$\wedge$ Values are expressed as mean \pm standard deviation $(n=3)$ oils but also carotenoid, chlorophyll and Pheophytin etc. which also act as a marker of the degree of ripening of sea buckthorn 14]. Now it is most cultivated crop in Canadian western provinces [15].

Sea Buckthorn oil extraction technology is not new as it has already been used for more than 50 years in Russia and it is further improved with advance techniques. All the nutrients extracted from Sea Buckthorn berries in soluble form and the presence of insoluble ingredients is negligible and this is one of the reasons why all of the extracted components works well. Lipophilic fractions of the soft parts and seeds also contain fatty acids especially palmitoleic acid, the oil extracted from the fruits is used for the treatment of digestive problems [16] and skin problems [17]. In many studies it has been observed that sea buckthorn berries oil extract evaluated through many in-vitro and in-vivo experiments in order to explore its mechanism of action for the treatment of type 2 diabetes mellitus [18] and also used in cancer therapy [19]. That plant is locally available and its cultivation can be increased by providing the friendly climate. Blending the Sea Buckthorn oil with any other edible oil a good nutrient oil can be produced. On the bases of Physico chemical properties we offer that sea buckthorn oil is the nonconventional source of edible oil with all nutritional values (Table 1). berries and other commercial importance [13, 


\section{Materials and methods}

All reagents of $(>95 \%)$ purity were purchased from Merck (Germany). Sea Buckthorn berries were collected from norther parts of Pakistan. The methods for processing of sea buckthorn berries for seed oil, pulp oil, animal feed, powdered nutrient supplement and juice are shown in a schematic diagram (Figure 1).

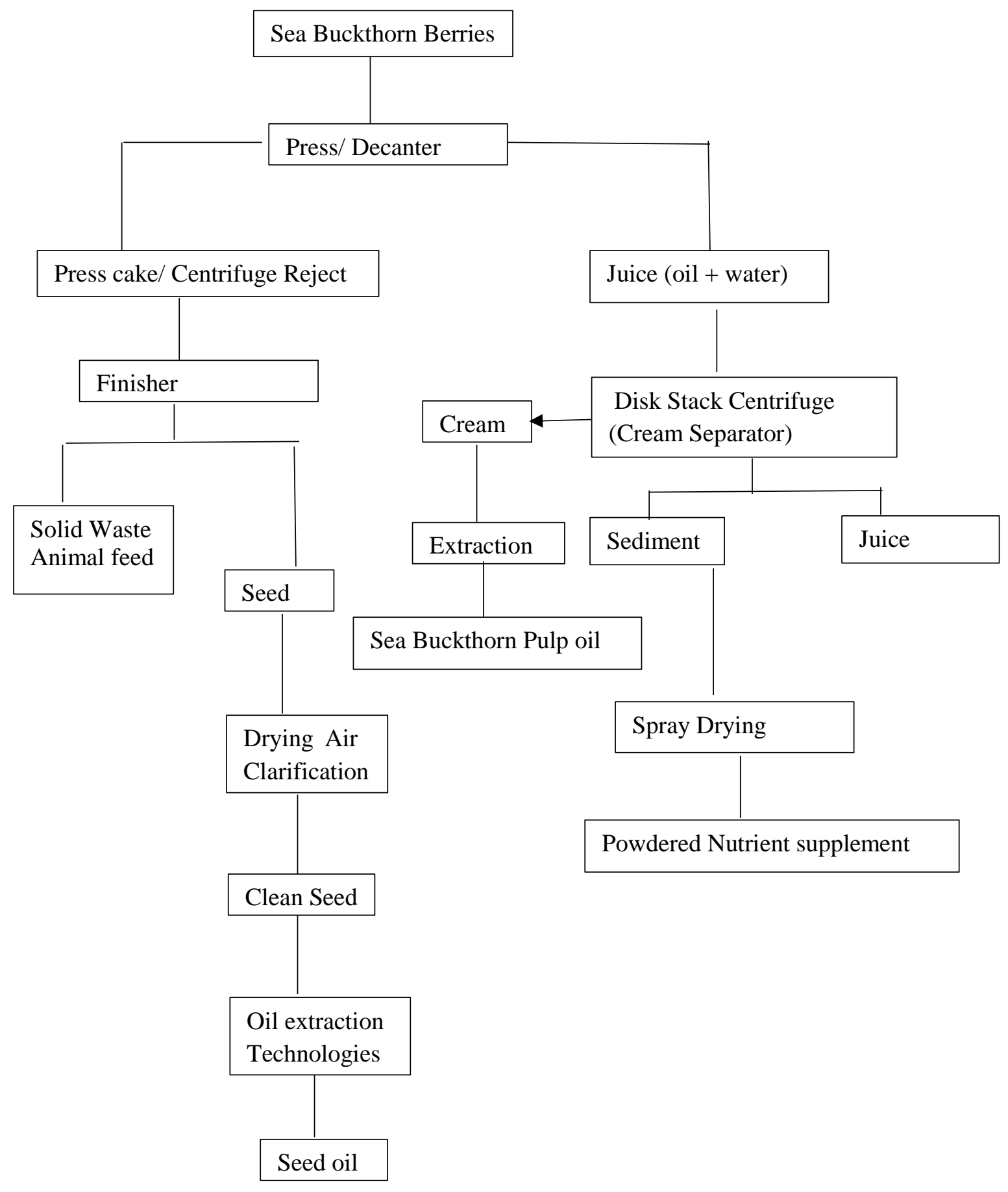

Figure 1. A schematic diagram shows of the method for processing of sea buckthorn berries for seed oil, pulp oil, animal feed, powdered nutrient supplement and juice 


\section{Processing of Sea Buckthorn berries}

$450 \mathrm{ml}$ of mixture of chloroform and methanol $(2: 1 \mathrm{v} / \mathrm{v}) \quad$ was used to extract oil from $50 \mathrm{gm}$ berries by stirring at room temperature for $2 \mathrm{hrs}$ on a magnetic stirrer. After filtration the residual material was treated with $100 \mathrm{~m} 1$ chloroform: methanol mixture. All the extracts were combined and washed consecutively with Folch solution to remove the non-lipid impurities. On removal of solvent under reduced pressure, the oil was stored in an inert atmosphere, to avoid polymerization [20].

\section{Free fatty acid value (FFA)}

Free fatty acid value of oil extracted from berries was calculated by titrating the extract against $0.1 \mathrm{~N}$ aqueous potassium hydroxide using $1 \%$ phenolphthalein as an indicator. Prior to titration the extract was first heated with neutralized alcohol before titration [21].

\section{Peroxide value}

To $1-2$ gms of extracted oil $25 \mathrm{ml}$ of acetic acid and chloroform : methanol mixture (2: $1 \mathrm{v} / \mathrm{v})$ was added in a $250 \mathrm{ml}$ Erlenmeyer flasks and swirled the flask until the sample was dissolved. $1 \mathrm{ml}$ of saturated potassium iodide solution was then added and allowed to stand with repeated shaking after every one minute. $35 \mathrm{ml}$ of distilled water was added to it and titrated against $0.02 \mathrm{~N}$ Sodium thiosulphate with constant and vigorous shaking till the disappearance of yellow color. $5 \mathrm{~m} 1$ of starch solution was added and titration was continued with vigorous shaking to titrate all the iodine from chloroform-layer. A blank was run with same quantity of reagents at the same time and under the same conditions [22].

\section{Iodine value}

Extracted oil (0.15-0.2 g) in $500 \mathrm{~m} 1$ iodine flask was taken and $15 \mathrm{~m} 1$ of carbon tetrachloride was added followed by $20 \mathrm{~m} 1$ of wiji's solution (dissolving 10 gram of iodine monochloride in $300 \mathrm{~m} 1$ of carbon tetrachloride and $700 \mathrm{ml}$ of glacial acetic acid. Strength of this solution was ascertained by titration with the standardized sodium thiosulphate solution); flask was encapped and swirled to insure an intimate mixture then allowed to stand for 2 hours in the dark at room temperature. After two hours $20 \mathrm{~m} 1$ of $10 \%$ potassium iodide solution was added followed by $100 \mathrm{~m} 1$ of distilled water. The liberated iodine in solution was titrated against $0.1 \mathrm{~N} \mathrm{Na}_{2} \mathrm{~S}_{2} \mathrm{O}_{3}$ which was added gradually with a constant and vigorous shaking. The titration was continued until the dark blue color faded. $5 \mathrm{~m} 1$ of $1 \%$ starch indicator solution was added and titration was continued until the disappearance of blue color. A blank was run with the same quantity of reagents at the same time and under the same condition.

\section{Saponification value}

$2 \mathrm{mg}$ of oil and exactly $25 \mathrm{ml}$ of alcoholic 0.5 $\mathrm{N} \mathrm{KOH}$ solution were added in a saponification flasks. Flasks were fitted with water cooled condenser and boiled continuously, until the sample was completely saponified. The flasks were then removed from the water bath and $1 \mathrm{ml}$ of $1 \%$ phenolphthalein indicator was added to each of the flask and titrated against $0.5 \mathrm{~N} \mathrm{HC} 1$. The volume of $0.5 \mathrm{~N} \mathrm{HCl}$ required for each flask titration was recorded. A blank determination was run with the same quantity of reagents at the same time and under the same condition [23, 24].

\section{Unsaponifiable matter}

$2.5 \mathrm{~g}$ of oil samples were taken in round bottom flasks. $5 \mathrm{ml}$ of $50 \% \mathrm{KOH}$ and then 30 $\mathrm{ml}$ of distilled alcohol were added. The flasks were equipped with a reflux condenser and were placed on a reflux water bath. The contents were refluxed for 1 hour. After reflux, poured it into a clogged cylinder. The volume was made to $40 \mathrm{ml}$ with distilled water. $30 \mathrm{ml}$ of hexane was then added. Well shaken with cap, remove the material until two layers separate. The top layer of hexane was removed by pipette and $30 \mathrm{ml}$ of hexane was then added, the process repeated. The 
hexane portion was collected each time and then treated with anhydrous sodium sulfate. It was repeated three times, collecting the hexane portions in a separatory funnel and giving three washes with distilled water. Filtered the hexane extract over anhydrous sodium sulfate (prepared by heating the sodium sulfate in a porcelain dish in an oven to remove traces of absorbed moisture). Unsaponifiable material was obtained after removal of hexane by evaporation.

\section{Preparation of methyl esters}

Methyl ester of different lipid classes and whole oil were prepared by treatment with boron tri fluoride in methanol. For this purpose, lipid classes and whole oil were dissolved in benzene in test tubes with Teflon lined screw caps 2-3 ml. BF3 solution in methanol was added in each test tube and tubes were closed tightly. All these tubes were heated in boiling water bath for recommended time for the completion of the reaction. After heating tubes were allowed to cool and esters were extracted with n-hexane. The extracts were washed with hexane for two times. After washing, the moisture was dried by adding anhydrous sodium sulphate and then filtered solvent was evaporated from filtrate by putting the sample on hot plate.

\section{Gas liquid chromatography}

1-2 $\mu \mathrm{l}$ of liquid sample i-e methyl ester was injected into the glass column with $15 \%$ diethylene glycol succinate, for each time. The temperature of column, injector and detector was maintained at $185-200{ }^{\circ} \mathrm{C}$ and $300{ }^{\circ} \mathrm{C}$ respectively. The carrier gas was nitrogen whose flow rate through the column was adjusted to $40 \mathrm{ml} / \mathrm{min}$. The chart speed was adjusted to $10 \mathrm{~mm} / \mathrm{min}$. The peaks recorded at shimadzu recorder C-R4A chromatopac, were identified by comparison of their retention times with those of standard methyl esters analyzed under the same conditions [25]. The area of each peak was calculated by the formula; Area of peak $=1 / 2$ $\mathrm{x}$ base perpendicular. Percent peak areas were quoted as fatty acid composition indicated by chromatograms (Figure 2), (British standard method of analysis of oils and fats, ISO 1958).

Thin layer chromatography (TLC)

The neutral lipids were separated on $0.5 \mathrm{~mm}$ thick TLC plates using hexane: ether: acetic acid (80:20:2 v/v) solvent system and sprayed with 2, 7 dichloro Phlorociene as the locating agent. Different classes of lipids were separated by calculating $\mathrm{R}$ value (Figure 3 ) [24].

\section{SAMPLE: Sea Buckthorn}

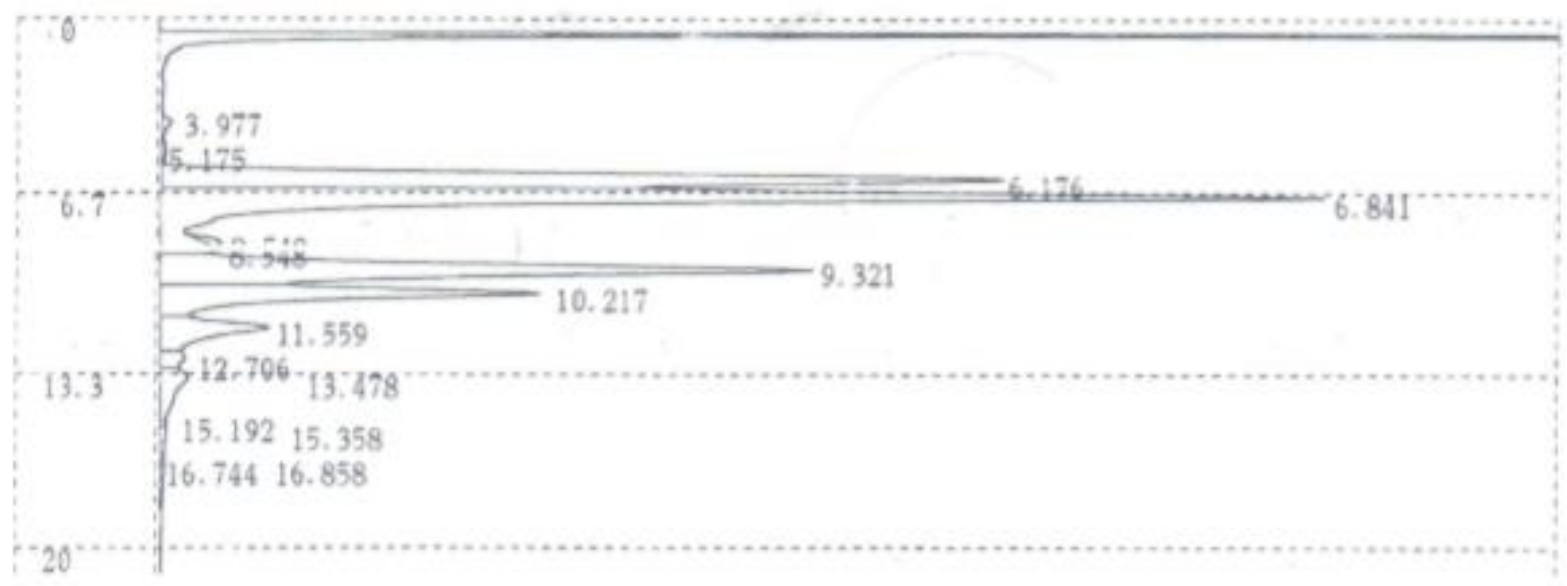

Figure 2. Gas liquid chromatography 
The area of each peak was calculated by the formula; Area of peak $=1 / 2 \times$ base perpendicular. Percent peak areas were quoted as fatty acid composition indicated by chromatograms (Table 2), (British standard method of analysis of oils and fats, ISO 1958).

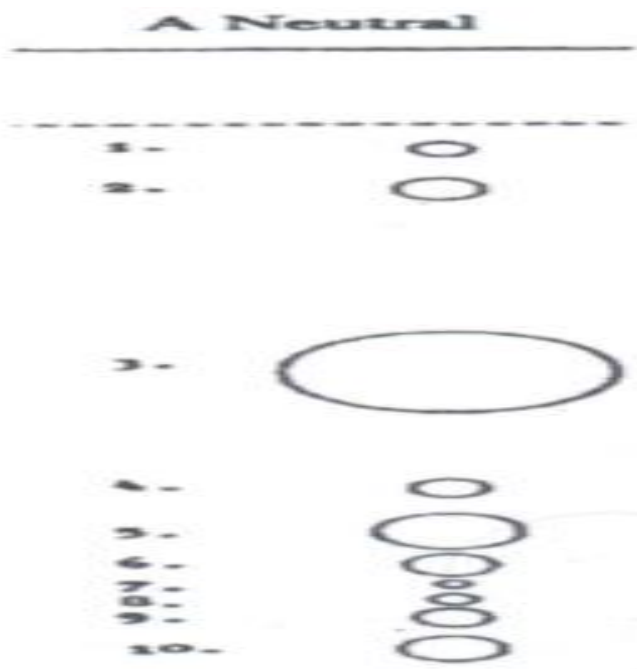

Figure 3. The neutral lipids were separated on $0.5 \mathrm{~mm}$ thick TLC plates

Table 2. Fatty acid composition indicated by chromatograms

\begin{tabular}{|c|c|c|}
\hline Fatty acid & Carbon number & Concentration in extract \\
\hline Palmitic acid & C16.0 & 10.98 \\
\hline Palmitoleic acid & C16.1 & 14.0 \\
\hline Stearic acid & C18.0 & 0.295 \\
\hline Oleic acid & C18.1 & 34.30 \\
\hline Linoleic acid & $\mathrm{C} 18.2$ & 11.51 \\
\hline Linolenic acid & $\mathrm{C} 18.3$ & 4.317 \\
\hline
\end{tabular}

\section{Thin Layer Chromatography}

Using hexane: ether: acetic acid (80:20:2 v/v) solvent system and sprayed with 2, 7 dichloro Phlorociene as the locating agent. Different classes of lipids were separated by calculating R value. Hydrocarbons, Waxes, Triglycerides, Free fatty acid, Sterol, Glucosides, Alcohol, 1,3 Diglycerides , 1,2 Diglycerides and Monoglycerides.

\section{Results}

Biochemical analysis indicated that the Free Fatty Acid Value of the oil was $11.28 \pm 0.3$ $\%$, Acid Value $22.48 \pm 0.5 \mathrm{mg} \mathrm{NaOH} / \mathrm{g}$, Peroxide Value $70 \pm 0.4 \mathrm{mg} \mathrm{KOH} / \mathrm{g}$, Iodine Value $80.49 \pm 0.3 \mathrm{~g}$ I2/100 g, Saponification Value $248.36 \pm 0.7 \mathrm{mg} \mathrm{KOH} / \mathrm{g}$,
Unsaponifiable Matter $3.03 \pm 0.03 \%$, Specific gravity $0.922 \pm 0.005 \mathrm{~g} / \mathrm{mL}$, Refractive Index at 28 oC $1.462 \pm 0.004$ and Moisture Content was $0.013 \pm 0.01 \%$

Thin layer Chromatography was used to study the lipid classes of the oils the results showed that $94 \%$ of neutral lipids were present in the oil and the main lipid classes were hydrocarbon, waxes, triglycerides, free fatty acids, diglycerides, sterols, monoglycerides. The GLC indicated that main fatty acids were Palmitic acid (10.98 \%), Palmitoleic acid (14.0\%), Stearic acid (0.295 $\%)$, Oleic acid $(34.30 \%)$, Linoleic acid (11.51\%) and Linolenic acid (4.317\%). Over 
all the $\%$ of saturated fatty acids was $12.0 \%$ and unsaturated fatty acids $88 \%$.

\section{Discussion}

The present work was conducted to investigate the Physico-chemical properties and fatty and composition of Sea Buckthorn. The plant was selected due to its medical significance and high nutritional value [26]. The yield of oil is $9.5 \%$ which indicates that that the oil is a good non-conventional source and helpful to decrease the demand of oil import in sector. The free fatty acids of the oil is $11.28 \%$ which is not good for the edible oil but it is acceptable in crude form. After refining the oil, the \%age of free fatty acid decreased and will be in acceptable range of edible oil. The peroxide value determines the formation of epoxide which on further oxidation changes into peroxide which causes the rancidity and decrease the shelf life of oil. The $70 \mathrm{meq} / \mathrm{Kg}$ of peroxide in crude form of Sea Buckthorn is acceptable. Iodine value determines the unsaturation of oil. The oil is a good combination of saturated and unsaturated fatty acids. Saponification value gives the idea of molecules present in the oil the value 248.36 shows that bigger molecule are present which are helpful if oil is heated at high temperature for frying purpose unsaponifiable matter is $3.03 \%$ which become less when oil is refined [27]. Specific gravity of the oil is 0.922 which is close to the edible oils. Moisture content of the oil is $0.013 \%$ which helps to stop the oxidation of the oil so increase the shelf life of the oil and minimize the character of rancidity. Refractive index of the oil shows the purity and it is 1.462 which is same as the edible oil. Thin layer chromatography results shows that $94 \%$ of neutral lipids present in the oil The GLC give the idea of fatty acids present in the oil [28]. The chromatograph shows that the main fatty acids are palmetic acid, stearic acid, oleic acid, linoleic acid, linolenic acid alongwith other palmetoleic acid ,arachidic acid and Myristic acid present in minor quantities. The $\%$ of saturated fatty acids is $12.0 \%$ and unsaturated fatty acids is $88 \%$. Among the unsaturated fatty acid the oleic acid (omega-3) is $34.30 \%$ which is in good \%age and helps to synthesize the omega- 6 and omega- 9 fatty acid in the body which cannot be synthesized by the body itself. The omega-6 (4.31\%) and omega-9 $(11.51 \%)$ which are essential fatty acids help to maintain the cholesterol in the body. It reduces the LDL (low density Lipoprotein) in the body by maintaining the level of HDL (High density lipoprotein) which minimizes the chances of cardio vascular diseases. The good quantity of saturated fat palmetic acid $(10.98 \%)$ is helpful to use the oil in confectionaries. So this oil can replace ghee thus safe energy and reduce the chances of trans fatty acids which form during the process of hydrogenation. Hydrogenation process produces trans fatty acids form which increases the LDL in blood serum. The present work indicated that the physicochemical values of the oil are not well within value reported in the literature but it is due to the state of i.e. crude and change of the climate from the others, but the oil does not seem the change its property and utilization as oil and medicine in recommended diseases [25].

\section{Conclusion}

The oil from the seeds of Sea Buckthorn were characterized and studied for its fatty acid composition by gas chromatography. The oil contained fatty acid, palmetic acid, oleic acid, linoleic acid, linolenic acid and stearic acid. Lipid classes were determined by means of thin layer chromatography the result showed that lipid classes present in the oil are hydrocarbon, waxes, triglycerides, free fatty acid, diglycerides, sterols and monoglycerides. The peroxide value, free fatty acid value, acid value of the oil are higher but after refining the oil may be well within the range of edible oil values while the saponification and iodine value shows the trend of the 
edible. Considering the experimental data it is suggested strongly that oil can be used for edible purpose after refining due to its ideal physico chemical values and health promoting fatty acid composition. Although the yield of the oil is not enough but the quantity is more enough to use the extracted oil after blending the oil with other edible oils (Canola, Sunflower, Soya beans and palm etc.).

\section{Authors' contributions}

Conceived and designed the experiments: $S$ Rashid \& A Arif, Performed the experiments: A Tabasum, Analyzed the data: H Zain \& M Shafeeq Ur Rahman, Contributed reagents/ materials/ analysis tools: $S$ Ehsan \& $S$ Rashid, Wrote the paper: H Zain \& A Arif.

\section{References}

1. Zielinska A \& Nowak I (2017). Abundance of active ingredients in seabuckthorn oil. Lipids Health Dis 16(1): 95.

2. Ursache FM, Ghinea IO, Turturica M, Aprodu I, Rapeanu G \& Stanciuc N (2017). Phytochemicals content and antioxidant properties of sea buckthorn (Hippophae rhamnoides L.) as affected by heat treatment - Quantitative spectroscopic and kinetic approaches. Food Chem 233: 442-449.

3. Dulf FV (2012). Fatty acids in berry lipids of six sea buckthorn (Hippophae rhamnoides L., subspecies carpatica) cultivars grown in Romania. Chem Cent J 6(1): 106.

4. Ran BB \& Li WD (2019). Research progress on chemical constituents and their differences between sea buckthorn berries and leaves. Zhongguo Zhong Yao Za Zhi 44(9): 1767-73.

5. Zeb A \& Ullah S (2015). Sea buckthorn seed oil protects against the oxidative stress produced by thermally oxidized lipids. Food Chem 186: 6-12.

6. Kruczek M, Swiderski A, Mech-Nowak A \& Krol K (2012). Antioxidant capacity of crude extracts containing carotenoids from the berries of various cultivars of Sea buckthorn (Hippophae rhamnoides L.). Acta biochim Pol 59(1): 135-7.

7. Larmo PS, Jarvinen RL, Setala NL, Yang B, Viitanen MH \& Engblom JR (2010). Oral sea buckthorn oil attenuates tear film osmolarity and symptoms in individuals with dry eye. J Nutr 140(8): 1462-8.

8. Patel CA, Divakar K, Santani D, Solanki HK \& Thakkar JH (2012). Remedial Prospective of Hippophae rhamnoides Linn. (Sea Buckthorn). ISRN pharmacol 436857.

9. Fatima T, Kesari V, Watt I, Wishart D, Todd JF \& Schroeder WR (2015). Metabolite profiling and expression analysis of flavonoid, vitamin $\mathrm{C}$ and tocopherol biosynthesis genes in the antioxidant-rich sea buckthorn (Hippophae rhamnoides L.). Phytochem 118: 181-91.

10. Ding J, Ruan CJ, Guan Y, Shan JY, Li H \& Bao YH (2016). Characterization and identification of ISSR markers associated with oil content in sea buckthorn berries. Genet Mol Res 15(3).

11. Chen C, Xu XM, Chen Y, Yu MY, Wen FY \& Zhang H (2013). Identification, quantification and antioxidant activity of acylated flavonol glycosides from sea buckthorn (Hippophae rhamnoides ssp. sinensis). Food Chem 141(3): 1573-9.

12. Upadhyay NK, Kumar MS \& Gupta A (2010). Antioxidant, cytoprotective and antibacterial effects of Sea buckthorn (Hippophae rhamnoides L.) leaves. Food Chem Toxicol 48(12): 3443-3448.

13. Andersson SO, Andren O, Lyth J, Stark JR, Henriksson M \& Adami HO (2011). Managing localized prostate cancer by radical prostatectomy or watchful waiting: Cost analysis of a randomized trial (SPCG-4). Scand J urol Nephrol 45(3): 177-83. 
14. Giuffrida D, Pintea A, Dugo P, Torre G, Pop RM \& Mondello L (2012). Determination of carotenoids and their esters in fruits of sea buckthorn (Hippophae rhamnoides L.) by HPLCDAD-APCI-MS. Phytochem anal 23(3): 267-273.

15. Beveridge $\mathrm{T}$, Harrison JE \& Drover J (2002). Processing effects on the composition of sea buckthorn juice from Hippophae rhamnoides L. Cv. Indian Summer. J Agric Food Chem 50(1): 1136.

16. Dannenberger D, Tuchscherer $M$, Nurnberg G, Schmicke M \& Kanitz E (2018). Sea Buckthorn Pomace Supplementation in the Diet of Growing Pigs-Effects on Fatty Acid Metabolism, HPA Activity and Immune Status. Int $J$ Mol 19(2).

17. Zhang J, Wang C, Sun B \& Qi C (2018). Understanding the role of extracts from sea buckthorn seed residues in antimelanogenesis properties on B16F10 melanoma cells. Food Funct 9(10): 5402-5416.

18. Gao S, Guo Q, Qin C, Shang R \& Zhang $Z$ (2017). Sea Buckthorn Fruit Oil Extract Alleviates Insulin Resistance through the PI3K/Akt Signaling Pathway in Type 2 Diabetes Mellitus Cells and Rats. J Agric Food Chem 65(7): 13281336.

19. Olasz EB, Babakoohi S \& Lazarova Z (2017). Keratinocyte Cancer Therapies Enter the Era of Targeted and Immunotherapy: Join the Club. JAMA Dermatol 153(4): 253-255.

20. Johansson AK, Korte H, Yang B, Stanley JC \& Kallio HP (2000). Sea buckthorn berry oil inhibits platelet aggregation. J Nutr Biochem 11(10): 491-495.
21. Cakir A (2004). Essential oil and fatty acid composition of the fruits of Hippophae rhamnoides L. (Sea Buckthorn) and Myrtus communis L. from Turkey. Biochem Syst Ecol 32(9): 809-816.

22. Gutiérrez L-F, Ratti C \& Belkacemi K (2008). Effects of drying method on the extraction yields and quality of oils from quebec sea buckthorn (Hippophaë rhamnoides L.) seeds and pulp. Food Chem 106(3): 896-904.

23. Yang B \& Kallio HP (2001). Fatty Acid Composition of Lipids in Sea Buckthorn (Hippophaë rhamnoides L.) Berries of Different Origins. J Agric Food Chem 49(4): 1939-1947.

24. Li TSC, Beveridge THJ \& Drover JCG (2007). Phytosterol content of sea buckthorn (Hippophae rhamnoides L.) seed oil: Extraction and identification. Food Chem 101(4): 1633-1639.

25. Smida I, Pentelescu C, Pentelescu O, Sweidan A, Oliviero $N$ \& Meuric $\mathrm{V}(2019)$. Benefits of sea buckthorn (Hippophae rhamnoides) pulp oil-based mouthwash on oral health. $J$ Appl Microbiol 126(5): 1594-1605.

26. Sola Marsinach M \& Cuenca AP (2019). The impact of sea buckthorn oil fatty acids on human health. Lipids Health Dis 18(1): 145 .

27. Chen L, Liu YL \& Deng JL (2019). Removal of phthalic acid esters from sea buckthorn (Hippophae rhamnoides L.) pulp oil by steam distillation and molecular distillation. Food Chem 294: 572-577.

28. Ding J, Ruan C, Du W \& Guan Y (2019). RNA-seq data reveals a coordinated regulation mechanism of multigenes involved in the high accumulation of palmitoleic acid and oil in sea buckthorn berry pulp. BMC Plant Biol 19(1): 207. 